tences in which it was contained. This is an obseivation which we have constantly the opportunity of rerifying. When a part upon which an artificial inoculation has been made, is made to slough, bJ the application of caustic, within four or five days of the infection, a simple core alone will ordinarily result. After the separation of the slough, the surface of the wound will not furnish an inoculable matter. In like manner, after natural inocular tion, if the part inoculated sloughs within the first few days, simple ulcer alone will be left. We find in such cases that there is no suppuration of the inguinal glands, because there is no ulceration of any infected part. There is no contamination of the system, because the virus, by means of which constitutional infection takes place, has been destroyed before the process has been gone through.

The three cases which we have now considered, may be regarded, as I have stated, as types of three very common classes of affections, differing in their mode of origin, in their effects upon the constitution, and in the treatment which they require.

The first presented in its origin a sore surrounded by specific adhesive inflammation. The glands of the groin were in a state of slight chronic enlargement, and the constitution was affected with syphilis.

The second originated in a sore presenting the characters of acute ulceration. The glands in the groin became infiamed and suppurated. But I venture to say there will be here no constitutional affection.

The third, as far as we have been able to learn, commences as a sloughing sore, and has been accompanied by neither inflammation of the inguinal glands nor syphilitic affection of the system. At our next meeting, I purpose to make some further remarks on the second of these three forms of disease.

\section{CASE OF DISLOCATION OF THE HUMERUS ON THE DORSUM OF THE SCAPULA.}

\section{By R. U. WEST, Esq.}

Distocations of the os humeri on the dorsum of the scapula are very rare; so much so, that Sir Astley Cooper, in his work on dislocations, says that there were only two such cases met with in Guy's Hospital during thirty-eight years. It would seem, therefore, that the accident can arise only from some peculiarity in the kind of violence which causes it, and not from the action of any particular muscles on the bone after it is thrown out of the glenoid cavity. The manner in which the accident was caused is not given in the two cases referred to by Sir Astley; but there are three other cases communicated to him by provincial practitioners, and published in his work, which seem to prove this ; notwithstanding that one of the writers, Mr. Coley of Bridgenorth, thinks that the effect is produced by the action of the latissimus dorsi and teres major on the bone. In fact, the very great frequency of the dislocation into the axilla, compared with that of the dislocation either backwards or forwards, must prove that the muscles invariably pull the arm downwards, when no other force gives a different direction to it. Surely, when the muscles are left to themselves, the pectoralis major would have its influence as well as the latissimus dorsi.

About three months ago, I met with a case of the dislocation backwards, and it occurred in a way which may serve to illustrate this point. My patient, a farmer, residing about a mile from this place, was standing alone in his rard, where some additions to his house were being erected. Four and twenty deal-boards were piled crosswise over a pole, which was supported at each end by a triangle; and as Mr. - stood with his back towards one of these triangles, it suddenly gave way; the pole dropped to the ground, the boards slided off the end of it, and the whole mass falling on him, threw him on his face to the ground. The intersecting portion of the boards caught him on the back, and held him down, while his head esceped from being arushed by being in the interval or interwtice above; bet the right shoulder, which was in the interral on one side, was on that very account severely injured, the elbow catching the ground, and the head of the humerus being thus driven directly beckwards. On my arrival about an hour after the accident, I found Mr. - suffering great pain both in the back and shoulder, and there was so much shortening of the upper arm, that before his coat was taken off, I thought the humerus must be broken. But on stripping him, the nature of the case was at once evident, from the great shortening of the limb, a soft, yielding, thickened, fleshy mass under the acromion, and, plainly perceptible under the spine of the scapula, a hard round lump, which could be made to rotate by grasping the elbow. There were some ribs broken, and the patient was collapsed and faint, so that I had no difficulty in reducing the dislocation, which I effected by means of a couple of jacktowels, and the assistance of two men from the yard. Mr. - had scarcely any pain in the shoulder after the reduction, and recovered very rapidly from all the effects of his accident.

This dislocation is easily detected and casily reduced, and the round lump on the dorsum of the scapula is very satisfactorily seen to disappear at the moment when the peculiar snap is heard, which announces the return of the head of the bone into its normal situation.

Alford, Lincolnshire, Dec. 20th, 1859.

\section{NOTES ON EPIDEMICAL DISEASES.}

By WHLLIAM ADDISON, M.D., F.R.S.

so. $I$.

INFLUENZA, ChOlERA, CONTINUED FEVER, TYPHUS, AGUE, REMITTENT FEVER, DIARRHEA, DYSENTERY, SMALL-POX, SCARLET FEVER, MEASLES, HOOPING-COUGH.

EpIDEmic, or, as they are now more usually termed by medical men, zymotic diseases, were formerly universally considered to be essentially different in their nature, each. being thought to depend on its own specific contagion. The correctness of this view seemed to be confirmed by the great apparent difference between typhus, scarlet-fever, influenza, and cholera. Subsequently it has been thought that all these diseases may derive their origin from some common agent, modified by peculiarities of climate and other circumstances, and which, under varying conditions, gives rise to various forms and types of disease. Whichever of these views be adopted, it is agreed by the most eminent investigators that there is a general resemblance between these various forms of disease, and that they have the following characters in common:They are all fevers; they all obey similar laws of diffusion; they all infest the same kind of places; they all attack the same classes, and for the most part persons of the like ages; and their intensity is increased or diminished by the same sanitary and social conditions. The consideration of these common properties of epidemical diseases, under whatever form or name they may occur, has led to the general conclusion, that the safeguard against them is sanitary measures; that is to say, measures which tend to remove those local conditions, without which, as experience has proved, pestilential diseases are incapable of existing.

The causes upon which epidemic diseases depend, their prognostics, and the phenomena attending them, we propose to consider under the following heads :-

I. An Epidenic Atmosphere.

II. Exdemic Atmospheres.

iII. Social Habits.

iv. Personal Cauges.

I. Epidemic Atmosphere. The first manifestations of an epidemic atmosphere in a country are usually certain natural phenomena, amongst the most remarkable of which are disturbancesin the physical condition of the air. These have been observed in ancient times to precede and accompany all great epidemics, and have been witnessed generally on the occur- 